\title{
Uniportal video-assisted thoracoscopic lower sleeve bilobectomy: a case report
}

\author{
Jesus Isea de la Viña ${ }^{1}$, Diego Gonzalez Rivas ${ }^{2,3}$ \\ ${ }^{1}$ Department of Thoracic Surgery, Clinical University Hospital of Valencia, Valencia, Spain; ${ }^{2}$ Department of Thoracic Surgery and Lung Transplant, \\ Coruña University Hospital and Minimally Invasive Thoracic Surgery Unit (UCTMI), Coruña, Spain; ${ }^{3}$ Department of Thoracic Surgery, Shanghai \\ Pulmonary Hospital, Tongji University School of Medicine, Shanghai, China \\ Correspondence to: Diego Gonzalez Rivas. Department of Thoracic Surgery and Lung Transplant, Coruña University Hospital and Minimally Invasive \\ Thoracic Surgery Unit (UCTMI), Coruña, Spain; Department of Thoracic Surgery, Shanghai Pulmonary Hospital, Tongji University School of \\ Medicine, Shanghai, China. Email: diego.gonzalez.rivas@sergas.es.
}

\begin{abstract}
Lower sleeve bilobectomy with bronchial re-anastomosis is performed classically through an open-thoracotomy approach. However, with the recently increased teaching, the experience in uniportal video-assisted thoracoscopic (UVATS) approach has disseminated. We, therefore, present a case report performed through this approach. A 65 -year-old male, with no relevant past medical history, pertinent comorbidities, and normal physical examination (PE). A high-resolution computed tomography (HRCT) and flexible bronchoscopy (FB) demonstrated a $2.8-\mathrm{cm}$ intraluminal lesion affecting the right main and intermediate bronchus very close to the orifice of the right upper lobe (RUL) bronchus, which was biopsied. The positron emission tomography computed tomography (PET-CT) demonstrated no positive lymph node activity. Differential diagnosis where establish with benign intraluminal tumors, however, histopathology revealed a squamous-cell carcinoma (SCC) of the lung. The patient was electively scheduled for surgery. Under general anesthesia and single-lung ventilation, a UVATS approach is made through the fourth intercostal space. An inferior bilobectomy was completed: the bronchial re-anastomosis of the right upper lobe was performed with a non-absorbable monofilament 3/0 anti-clockwise running suture. Complete lung re-expansion was achieved and no air leak identified. Surgery runtime of 121 minutes with minimal blood loss. In-hospital length-of-stay was four days without complications. A satisfactory chest X-ray (CXR) postdrain removal was achieved. We concluded that the sleeve inferior bilobectomy is a lung sparing-technique that can be safely performed through a UVATS approach as a reasonable alternative to the open approach with quicker recovery; however, it must be performed by surgeons with experience in UVATS procedures.
\end{abstract}

Keywords: Uniportal; sleeve; lobectomy; video-assisted; case report

Received: 22 January 2020; Accepted: 18 August 2020; Published: 20 April 2022.

doi: 10.21037/jovs-20-45

View this article at: http://dx.doi.org/10.21037/jovs-20-45

\section{Introduction}

Minimally-invasive (MI) uniportal video-assisted thoracoscopic (UVATS) approaches have surged in popularity in the last years. Nowadays, more complex procedures are performed commonly by different teams worldwide with a variety of levels of experience $(1,2)$. Lower sleeve bilobectomy and bronchial re-anastomosis for central lung tumors are historically performed through an open thoracotomy approach. The preference to perform a sleeve procedure over a pneumonectomy is overall the fact to preserve lung parenchyma and therefore decrease postoperative and overall mortality of patients (3). Particularly, in this case, what it makes it unique is the difficulty of the dissection with the inability to perform a pneumonectomy in this patient do to its poor tolerance.

There have been several recent publications regarding the procedure protocol, common complications and tips and tricks of general lung sleeve procedures (1-4). 

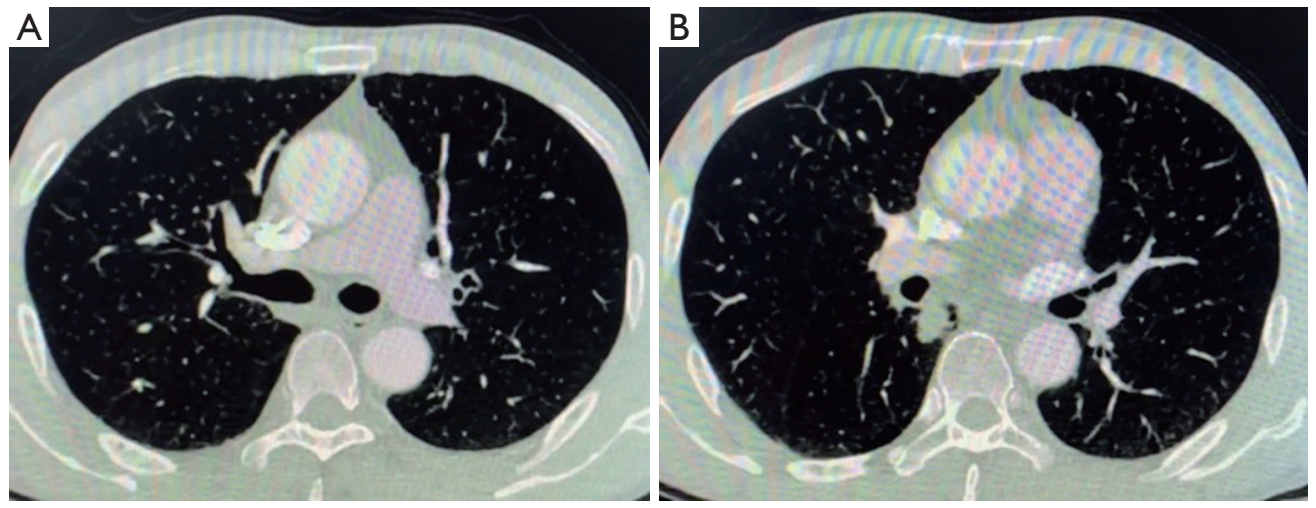

Figure 1 Preoperative patient CT scan. (A) CT shows right upper lobe bronchus free of disease; (B) the tumor is in close contact with the intermediate bronchus.

However, the variety of findings in each patient regarding the location and size of the lesion, the nodule extension and position regarding the hilum, the vessel anatomic variation and distribution between the hilum, the behavior of the lung during single-lung ventilation among others makes each case unique. Therefore, we contribute with this case performed through a UVATS approach. We present the following article in accordance with the CARE reporting checklist (available at https://jovs.amegroups. com/article/view/10.21037/jovs-20-45/rc).

The reason we choose to perform the sleeve procedure through a UVATS are as follows:

(I) Resembles movements made during open procedures;

(II) Less tissue damage;

(III) Less postoperative pain;

(IV) Minimal wound and scar, and better cosmesis;

(V) Increased recovery with shorter length-of-stay (LOS);

(VI) Less immediate postoperative complications;

(VII) Same oncologic resection principles.

\section{Case presentation}

A 65-year-old male, with no previous medical history and a primary unremarkable physical assessment is diagnosed with a $2.8 \mathrm{~cm}$ squamous-cell carcinoma (SCC) of the lung that affects the right main and intermediate bronchus very close to the orifice of the RUL bronchus (Figure 1). All procedures performed in this study were in accordance with the ethical standards of the institutional and/or national research committee(s) and with the Helsinki Declaration (as revised in 2013). Written informed consent was obtained from the patient for publication of this case report and accompanying images. A copy of the written consent is available for review by the editorial office of this journal.

\section{Preoperative preparation}

Regular preoperative workup of lung cancer was completed. A flexible bronchoscopy (FB) demonstrated that the right upper lobe (RUL) bronchus was free of disease. No lymph node activity on PET-CT. Good lung function tests and overall good surgical tolerance was confirmed.

High-resolution computed tomography (HRCT) and preferably three-dimensional $(3 \mathrm{D})$ reconstruction, if available, would be valuable in preoperative planning in order to determine: vessel position and potential branches or anatomic variations, pathologic lymph node presence, extension or infiltration, bronchial margins, blood supply and extension to clear and prepare for re-anastomosis. Table 1 shows specific equipment required at-a-glance. The potential unanticipated adverse event expected was the difficulty of the dissection and potentially the extension of the surgery timespan.

\section{Procedure}

The patient is placed in the surgical table on the known well-diffused UVATS position: lateral decubitus with arms flexed and stretched toward the head, with appropriate joint support. The surgeon is positioned in front of the patient, the assistant in the back of the patient in front of the surgeon but watching the same monitor, while the scrub nurse stands opposite to the surgeon at the level 
Table 1 Equipment flashcard

\begin{tabular}{ll}
\hline Equipment & \multicolumn{1}{c}{ Description } \\
\hline Camera & $\begin{array}{l}\text { Full high-definition (HD) thoracoscopic camera } \\
\left(\text { Karl Storz }^{\circledR}\right)\end{array}$ \\
Instruments & $\begin{array}{l}\text { UVATS surgery instruments (Shanghai Medical } \\
\text { Instruments Group Ltd.) }\end{array}$ \\
Staplers & $\begin{array}{l}\text { Endo GIA 30-45 mm staplers (Covidien- } \\
\text { Medtronic) }\end{array}$ \\
Energy & Harmonic energy device (Ethicon Endo-Surgery) \\
Clips & Corrugated clips Click aV (Grena $^{\circledR}$ ) \\
Sutures & $\begin{array}{l}\text { Prolene }{ }^{\circledR} \text { Non-absorbable monofilament 3/0 } \\
\text { running suture (Ethicon Inc) }\end{array}$ \\
\hline
\end{tabular}

UVATS, uniportal video-assisted thoracoscopic.

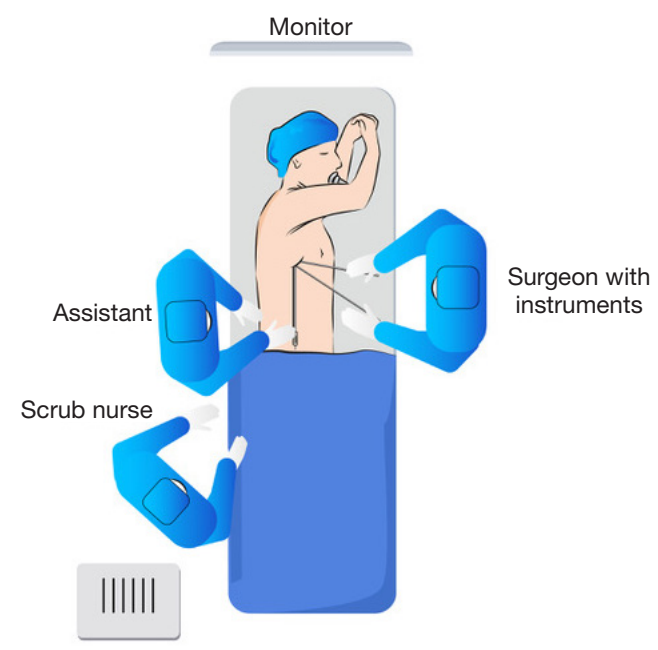

Figure 2 Theatre members are displayed as in the image.

of the knees of the patient (Figure 2). This allows less body interference between the surgeon and the assistant, facilitating comfortability during the procedure (5). The monitor is positioned above the head of the patient, at the top of the table, so that all the team can see the same monitor simultaneously.

The surgical table is flexed in wedge-shaped position to allow better spreading of the intercostal spaces. General anesthesia (GA) and single-lung ventilation (SLV) are required. Initially, there is no need for table rotation but during re-anastomosis, rotating away or towards the surgeon may facilitate the exposure during suturing (3).

A UVATS approach is performed through the fourth right intercostal space at the level of the mid-axillary line.
A wound protector was used. The pleural cavity was found free of adhesions. The surgery starts with the release of the pulmonary ligament, which will minimize the tension of the future re-anastomosis and lymphadenectomy on stations 8 and 9 . The inferior pulmonary vein is identified and isolated, performing its section with Endo GIA ${ }^{\circledR}$ $30 \mathrm{~mm}$ stapler. Dissection of the inferior and posterior aspect of the pulmonary hilum until identifying the main bronchus, where the described tumour causes retraction of the fissural confluence. Posteriorly, the azygos vein is tied and controlled with corrugated clips Click aV, $\left(\right.$ Grena $\left.^{\circledR}\right)$ for its release from the surrounding tissues. Subsequently, the superior aspect of the pulmonary hilum is released to achieve complete circumferential exposure. Lymphadenectomy on stations 2, 4 and 10 is performed. Posteriorly, the minor fissure is dissected and sectioned with Endo GIA ${ }^{\circledR} 45 \mathrm{~mm}$. The middle lobe vein is also cleared with Endo GIA ${ }^{\circledR} 30 \mathrm{~mm}$. At this point, the right upper lobe is isolated from the fissures of the rest of the specimen.

Subsequently, the truncus anterior (mediastinal artery, or Boyden trunk) is identified and preserved. Continuing the dissection for the identification of the intermediate artery pulmonary above the outlet of the middle lobe branch at the inter-fissural level, Endo GIA ${ }^{\circledR} 30 \mathrm{~mm}$ stapler section. This exposes the intermediate bronchus at the anterolateral level and given the absence of macroscopic disease, manual section is performed with scissors of the upper lobar bronchus and main bronchus. The rest of the specimen is removed en-bloc and is sent to deferred histological study. After completing the preparation of both bronchial stumps, the bronchial re-anastomosis is commenced (Figure 3). A running suture with $3 / 0$ non-absorbable monofilament is started at the posterior aspect of both bronchi in order to fully expose the total circumference of the bronchi and facilitate the completion of the anastomosis (Figure 4). Stitches are started in an "inside-out" fashion, taking the whole wall of the bronchus (full-thickness) connecting accordingly "outside-in" (3) distally. In addition, sewing is performed with the bronchial tubes and vessels aligned to avoid vascular bending and its consequences. Suturing is continued with the same needle in an anticlockwise direction. After the end of bronchial re-anastomosis, the pulmonary re-expansion is achieved without identifying any anastomotic or fissural air leak. A 28-french Argyle ${ }^{\circledR}$ chest tube was left in situ (Figure 5).

The total surgery runtime was 121 minutes with minimal blood loss. The patient was extubated in theatre and 


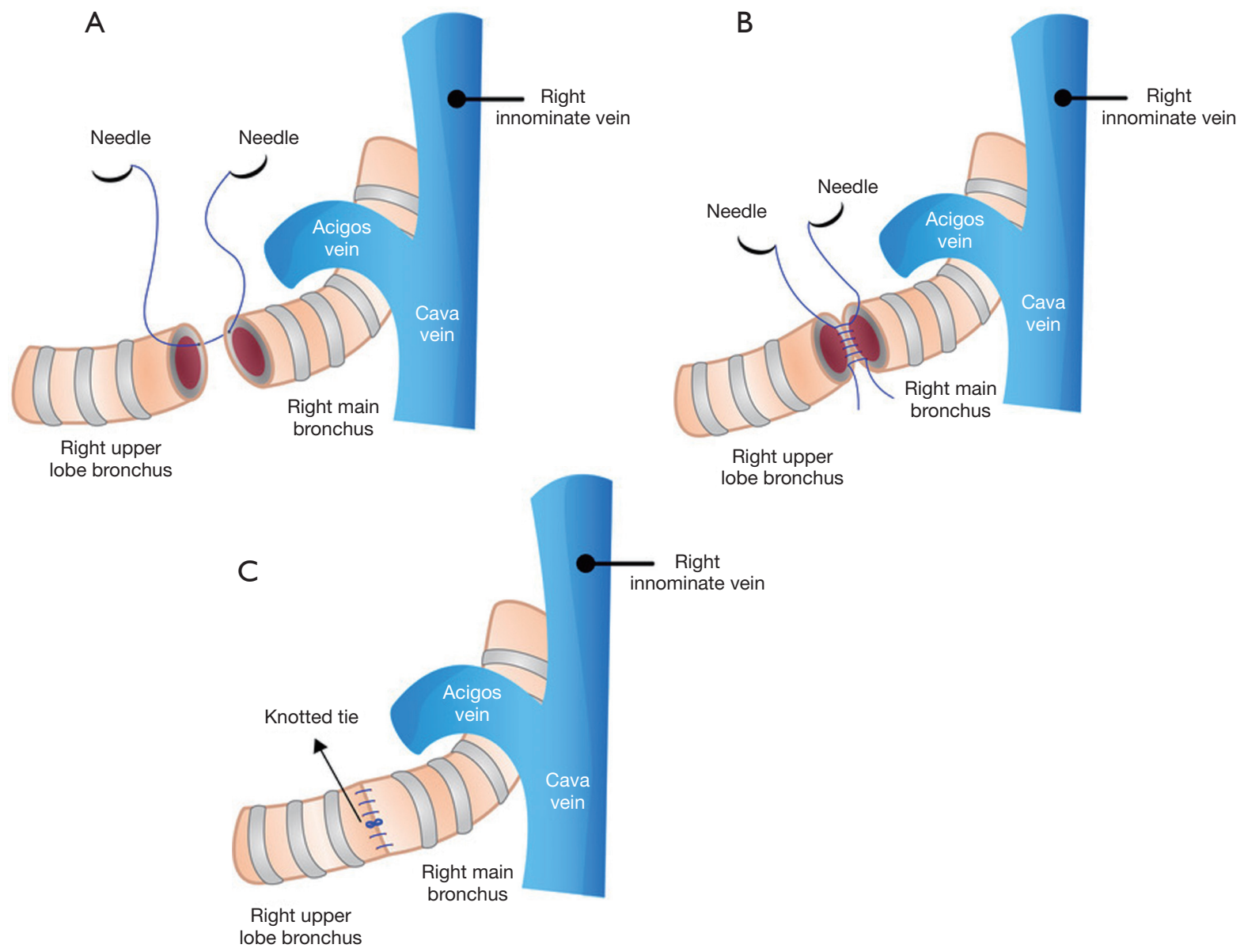

Figure 3 General picture of bronchial re-anastomosis. (A) Bronchial re-anastomosis. Suture is commenced at the posterior aspect of both bronchi. The pulmonary artery is intentionally omitted for graphic purposes; (B) re-anastomosis stitches are performed in an "inside-out" fashion, taking the whole wall of the bronchus (full-thickness) connecting accordingly outside-in 3 distally; (C) re-anastomosis is completed, and both ends of the suture are tied with a knot pusher.

transferred afterwards to the recovery unit.

\section{Post-operative management}

A routine postoperative chest $\mathrm{X}$-ray showed lung expansion in lack of pathologic findings (Figure 5). The patient had a normal uncomplicated postoperative course, being discharged four days after surgery. The final histology report confirmed the preoperative findings achieving complete resection with bronchial margins free of disease.

\section{Tips, tricks and pitfalls}

(I) Identify the vessels: right lower, middle and upper vein and artery;
(II) Achieve fissural isolation of the right upper lobe before sectioning the bronchus Divide the intermediate artery above A4-A5, preserving A1-A3;

(III) Complete the dissection of the posterior parenchyma between the upper and lower lobe;

(IV) Identify the intermediate bronchus and middle lobe bronchus;

(V) Grasp the lung parenchyma and push the lung upwards and posteriorly in order to have enough space and to have a good explosion for cutting the bronchus (5);

(VI) Performed the running suture starting at the posterior aspect of both bronchi and avoid vascular kinking;

(VII) Stitch in "inside-out" proximally, "outside-in" (3) distally with an anti-clockwise direction;

(VIII) Confirm no anastomotic air leak is present. If so, re- 


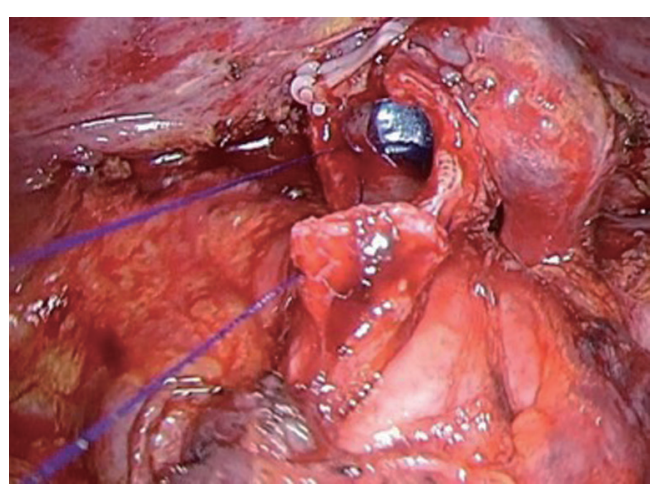

Figure 4 The running suture is started at the posterior aspect of both bronchi.

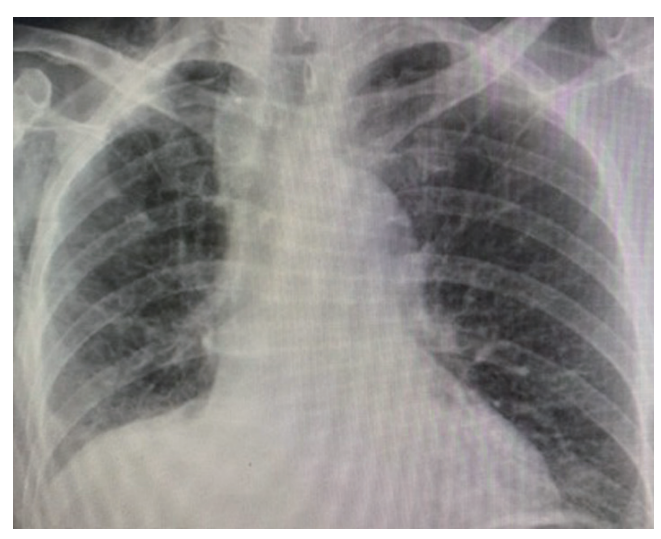

Figure 5 Postoperative chest X-ray.
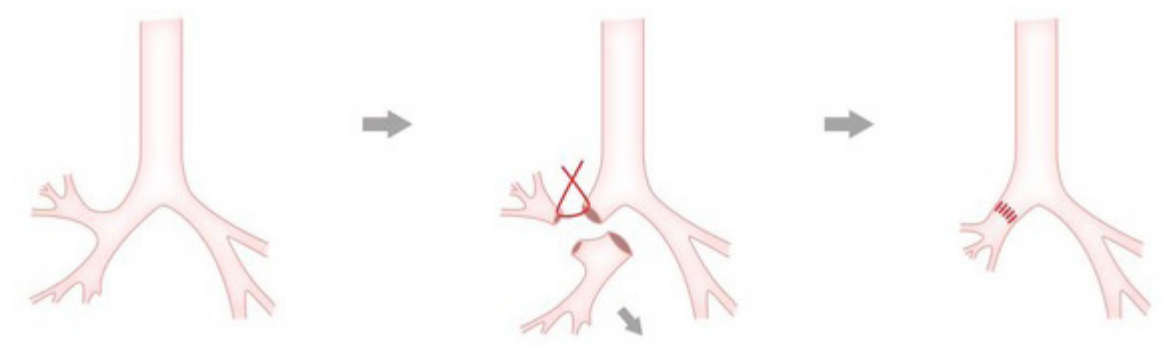

Figure 6 The sleeve inferior lobectomy procedure summarized.

stitch or repair.

A brief technique of the anastomosis summary is depicted in Figure 6.

\section{Conclusions}

Bilobectomy sleeve resection performed through a UVATS approach is feasible, safe and offers the same oncological principles as of open classical technique. It's effective and indicated for those patients with central airway lesions, However, it must be performed in the hands of experienced teams, but the dissemination of the technique will allow lessexperienced surgeons to analyze its reproducibility and as a final objective to offer an alternative to a wider resection, where patient safety is guaranteed. However, it is capital to consider that, in the case of any complication, there should be no hesitation to reconvert to a more extensive approach.

\section{Acknowledgments}

Funding: None.

\section{Footnote}

Reporting Checklist: The authors have completed the CARE reporting checklist. Available at https://jovs.amegroups. com/article/view/10.21037/jovs-20-45/rc

Conflicts of Interest: Both authors have completed the ICMJE uniform disclosure form (available at https:// jovs.amegroups.com/article/view/10.21037/jovs-20-45/ coif). DGR serves as an unpaid Associate Editor-in-Chief of Journal of Visualized Surgery. The other author has no conflicts of interest to declare.

Ethical Statement: The authors are accountable for all aspects of the work in ensuring that questions related to the accuracy or integrity of any part of the work are appropriately investigated and resolved. All procedures performed in this study were in accordance with the ethical standards of the institutional and/or national research committee(s) and with the Helsinki Declaration (as revised in 2013). Written informed consent was obtained from the patient for publication of this case report and accompanying 
images. A copy of the written consent is available for review by the editorial office of this journal.

Open Access Statement: This is an Open Access article distributed in accordance with the Creative Commons Attribution-NonCommercial-NoDerivs 4.0 International License (CC BY-NC-ND 4.0), which permits the noncommercial replication and distribution of the article with the strict proviso that no changes or edits are made and the original work is properly cited (including links to both the formal publication through the relevant DOI and the license). See: https://creativecommons.org/licenses/by-nc-nd/4.0/.

\section{References}

1. Gonzalez-Rivas D, Yang Y, Stupnik T, et al. Uniportal

doi: $10.21037 /$ jovs-20-45

Cite this article as: de la Viña JI, Gonzalez Rivas D. Uniportal video-assisted thoracoscopic lower sleeve bilobectomy: a case report. J Vis Surg 2022;8:21. video-assisted thoracoscopic bronchovascular, tracheal and carinal sleeve resectionst. Eur J Cardiothorac Surg 2016;49 Suppl 1:i6-i16.

2. Soultanis KM, Chen Chao M, Chen J, et al. Technique and outcomes of 79 consecutive uniportal video-assisted sleeve lobectomies. Eur J Cardiothorac Surg 2019;56:876-82.

3. Soultanis KM, Gonzalez-Rivas D. Uniportal video-assisted sleeve resections: how to deal with specific challenges. J Thorac Dis 2019;11:S1670-7.

4. Ismail M, Swierzy M, Nachira D, et al. Uniportal videoassisted thoracic surgery for major lung resections: pitfalls, tips and tricks. J Thorac Dis 2017;9:885-97.

5. Xu G, Chen H, Zheng B, et al. Recommendations for camera-holding during single-port video-assisted thoracoscopic lobectomy for non-small cell lung cancer. Video-assist Thorac Surg 2017;2:24. 